\title{
The Relationship between Self-Esteem and Academic Achievement in the Scientific Concepts and Methods of Teaching Course among Female Students of the Class- Teacher at the University of Jordan
}

\author{
Adnan Salem Al doulat ${ }^{1}$ \\ ${ }^{1}$ School of Educational Sciences, University of Jordan, Amman, Jordan \\ Correspondence: Adnan Salem Al doulat, Faculty of Educational Sciences, University of Jordan, Amman, Jordan. \\ E-mail: a.doulat@ju.edu.jo
}

Received: December 14, 2017

Accepted: December 29, 2017 Online Published: January 30, 2018

doi:10.5539/mas.v12n2p164

URL: https://doi.org/10.5539/mas.v12n2p164

\begin{abstract}
The study aimed to discover the relationship between self-esteem and academic achievement in the scientific concepts and methods of teaching course among the female students of the class teacher at the University of Jordan. The study included a sample of (68) female students. Academic marks has been recorded in the course of scientific concepts at the end of the first semester of the academic year 2016/2017, and the appropriate statistical analysis has been conducted for the purposes of the study. The results showed that the level of self-esteem for the students of the class teacher was high and there is a significant correlation between academic achievement and self-esteem.

The study recommended conducting further studies on other variables. Such as the relationship of the level of self-esteem to the degree of understanding of science processes and the degree of understanding of the nature of science.
\end{abstract}

Keywords: self-esteem, students of class teacher, academic achievement, scientific concepts.

\section{Introduction}

The human personality is a formative phenomenon that includes the interaction between the individual and his physical, psychological and social environment. It represents the framework of the individual, in which his psychological, social and mental nature is organized (Shagfah, 2008).

The interaction between the experiences by the individual and the knowledge acquired intentionally and unintentionally confronts the various environmental stimuli, leading to responses that indicate how unique this interaction has been in a particular situation. This means that the natural growth of the personality is done only by interaction between workers the two main characteristics are inheritance and experience.

Self-realization is the goal that man seeks in the sense that self-realization is the best form of balance, integration and homogenous conglomeration of all aspects of personality (Mustafa Fahmi, 1979).

Caring about every person and preparing him to reach a state of cognitive equilibrium and thus adapt to the natural and social environment is one of the objectives of education, and the goal of achieving an individualized personality formation of differences will only be achieved by developing aspects of his personality. The positive self-esteem is higher than the aspects that may be important, The educational system takes into account the development of the personality of the individual, (Wiggins and Schatz, 1994).

Self-esteem is a more comprehensive concept of the Self Concept and it is considered part of its dimension. Self-esteem is an important aspect in it, and it is closely related. The self- concept refers to the self-image of the individual and evaluates it. (Abu Zeid, 1987)

the concept of self-esteem resulted from the basic needs of man, and has been addressed by many of the theorists in the field of psychology in general, such as "Maslow" who designed the ladder of needs, so the definition of self-esteem differed by the researchers and this difference is due to the dimensions that they think they form, And others defined it as based on a sense of value, as defined by others as a recipe based on a sense of worth and efficiency (Yeshodhara, \& Vishalakshim, 2012) 
Rosenberg (1963) defines self-esteem as a sense of worth and self-esteem is either a positive or a negative one, which is one's sense of value and self-respect for what it is.

Abu Jahl (2003) refers to self-esteem as a self-determination of the individual in an attempt to adhere to this design, with the positives that invite him to respect himself compared to others, while this design also includes disadvantages that do not diminish among others while seeking To get rid of it.

The Self-Esteem concept represents a great importance to all educators and parents. Taking into consideration the Working to make students feel positive contributes to their abilities and aptitudes in all fields. Many studies have shown that high self-esteem leads to greater efficiency and effectiveness. In dealing with many stresses of life (Rahmani, 2011).

Self-esteem acts as a driving force. And this is due to that the way in which the individual lives is influenced by the way he conducts himself. His behaviour is how he perceives himself in view of the nature of the interactive, interactive relationship between self-esteem and behaviour (McDaniel, 1973).

Odeh and makkawi (1992) defines academic achievement as the knowledge acquired by the individual during his / her learning period for a particular subject or group of educational studies that the individual learns in a semester, year of study, or study stage

Al-Jalani (2016) added that the level of academic achievement reached by the student depends not only on his level of mental energy, but also on the level of variables such as motivation, emotional and social variables and self-esteem. This means that academic achievement is a multi-variable phenomenon, some cognitive mentality and other emotional motivation and other components of personality.

Thus, the relationship between self-esteem and academic achievement has been characterized by the interest of many studies that found that high self-esteem facilitates academic attainment and that there is a positive relationship between them. The concept of self is generally important in achievement. The high self concept has high academic achievement (Bankston \& Zhou, 2002)

In this regard, the results of several studies (Habibollah, 2009, Ashtiani, 2007, Marjorie, Philip, Herbert, Rhonda, \& Alexander, 2014; Martins, Peixoto, Pereira, Amaral \& Pedro, 2010; Ganaim ,2010) have shown that The level of self-esteem of students is related to the level of academic achievement, as the experience of success drives students to develop positive feelings and attitudes towards themselves and those with high academic achievement had a high appreciation.

The study of Aryana (2010) aimed to identify the relationship between the concept of self and academic achievement in a sample of pre-school students in Azerbaijan, which was conducted on a sample of 100 students. The results showed that there is a statistically significant difference between the concept self and achievement and that the concept of self in general is important in achievement, as the owner of the concept of high self has a high academic achievement.

The study of Parvaneh Doodman el al. (2017) investigated the relationship between self-esteem and academic achievement among high school students in Lamerd. The statistical population consisted of 300 students in Lamerd both girls and boys. 169 students were selected as statistical sample randomly, 73 boys and 96 girls. The results of their study showed that there is a significant relationship between components of susceptibility and competence with academic achievement.

By presenting the results of previous studies, we conclude that it is relatively common to conclude that the relationship between self-esteem and academic achievement is positive, although there is a slight variation in the results of some studies.

Thus, the present study comes as one of the research seminars in this aspect, especially as it dealt with a sample of university students specialized teacher grade, and seeks to reveal the relationship between self-esteem and academic achievement in the subject of scientific concepts.

\section{Problem of the Study}

High self-esteem is characterized by pleasure in interacting with others, comfortable with social attitudes, participation in groups of activities, and are often looking for new interests and finding solutions to the problems they face. They are also characterized by positive, optimistic talk, away from frustration, complaining and pessimism, and are also characterized by an awareness that is reflected in increasing their attention to the task, which has a strong impact on the individual's perception, motivation, and emotions (Vialle, Heaven, \& Ciarrochi, 2005).

Many studies have found that there is a positive correlation between academic achievement and self-esteem, and 
that students with high academic achievement have a high level of appreciation (Katrin, Seeshing, Nagengast, \& Hasselhorn, 2013; van, 2000, Worrell, 2007; Margaret \& Jean , 2011; However, most of these studies did not refer to the relationship between self-esteem and academic achievement in scientific concepts. Therefore, the researcher decided to study the relationship between self-esteem and academic achievement in the scientific concepts and methods of teaching material among sample of students of the class- teacher at the University of Jordan. Therefore, the problem of the study is to answer the following questions:

1.What is the level of self-esteem among female students of the class- teacher in the scientific concepts and methods of teaching course?

2. What is the level of academic achievement among female students of the class- teacher in the scientific concepts and methods of teaching course?

3. Is there a relationship between the level of self-esteem and academic achievement among the female students of the class- teacher in the scientific concepts and methods of teaching course?

\section{Importance of Studying}

The importance of this study in terms of the composition and development of the basic scientific concepts of the school students in the fields of physics, chemistry and biology of life on the one hand a second, In order for students to achieve effective teaching and to help students at this stage to develop sound scientific concepts and acquire them, they are required to feel their value and importance in producing generations and the importance of self-esteem in a positive way that enables them to help their students to acquire the correct scientific concepts in effective ways. Hence the importance of the study in identifying the relationship between self-esteem among students of the class teacher and their academic achievement in the course of scientific concepts and methods of teaching.

\subsection{Definitions}

Self-esteem: the image through which the individual is linked to his or her potential and personal abilities (Arabiya and Zoghul, 2008).

Academic Achievement: The knowledge gained by the individual during his / her learning period for a given subject or group of educational subjects studied by the individual in a semester, academic year, or re-education course (1992). The final mark obtained by the teacher of the class in a course of scientific concepts and teaching methods the end of the first semester of the academic year 2017/2016.

Students of the class teacher: are the students who are enrolled in the program "class teacher " and enrolled in the course of scientific concepts and methods of teaching for the first semester of the academic year 2017/2016.

Self-Esteem Level: The grade obtained by the class teacher on the self-assessment scale used in this study.

Study sample:

The study population reached (93)female students of the class- teacher in the University of Jordan registered in the course of scientific concepts and its methods of teaching during the academic year 2017/2016. Exclude (25)female students randomly to form the scouting sample, so the study sample becomes (68) female students.

Limitations and determinants of the study:

This study was applied in the first semester of the academic year 2016/2017 on a sample of female students of the class- teacher in the Faculty of Educational Sciences at the University of Jordan, in the course of scientific concepts and its methods of teaching. The results of this study are determined by the sample and tool, and their psychometric characteristic.

Study tool:

The researcher used the self-steam scale prepared by Dr. Ahmed Mohamed Saleh(1995).

\subsection{Validity of Measurement}

The scale shall be in its primary form from (60) paragraphs, and for the purposes of the test of the validity of the building was applied to a sample of (25) individuals and calculated the correlation coefficients of their answers to each of the paragraphs of the scale with the total score. The result shown that the correlation coefficients have paragraphs with low correlation, where the researcher deleted the paragraphs with correlation coefficients less than (0.20) Thus, there remained (42) paragraph of which the measure in its final form after being presented to (10) of the competent arbitrators and take their comments.

Extracting measurement scale: 
After applying the scale to the sample, one score was given to answer (yes), zero to the positive wording in the scale, zero to yes and one to the negative wording. Thus, the scores on the scale ranged from $0-42$. The researcher adopted the criterion: 0-13 low estimate, 14-27 average estimate, 28-42 high estimates, to interpreting the scores of the scale.

\subsection{Reliability}

The coefficient factor (Kronbach alpha) was extracted for students in the scientific concepts course reached 0.82 so It is considered suitable for this study.

\section{Results}

Question 1: What is the level of self-esteem among female students of the class- teacher in the scientific concepts and methods of teaching course?

To answer this question, the preparation of the students of the class teacher in the course of the scientific concepts and methods of teaching according to levels of self-assessment and Table (1), which shows the results

Table 1. Distribution of female students of the class- teacher in scientific concepts and methods of teaching course According to the level of self-esteem

\begin{tabular}{lll}
\cline { 1 - 2 } \multicolumn{2}{l}{ students of the class- teacher } & level \\
\cline { 1 - 2 } Ratio\% & number & \\
\hline 0 & 0 & Less than 13 (low) \\
20.6 & 14 & From 13 to Under 27 (Average) \\
79.4 & 54 & From 27 and above (high) \\
100 & 68 & Total \\
\hline
\end{tabular}

The results in the above table show that (14) students had average levels of assessment with a percentage of $20.6 \%$ and (54) students with levels of appreciation with a high percentage of $79.4 \%$ and no student with a low level of assessment.

It was found that the level of self-assessment of the students of the class teacher in the course of scientific concepts and methods of teaching was high, with an average of 31.28 , which is a high level according to the criterion used in the study.

Table 2. The averages and standard deviations of the scales of self-steam among female students of the class teacher in scientific concepts and methods of teaching course

\begin{tabular}{lll}
\hline standard deviations & averages & Items \\
\hline 0,34 & 0.87 & 1 \\
0,50 & 0.53 & 2 \\
0,37 & 0.84 & 3 \\
0,46 & 0,29 & 4 \\
0.24 & 0,94 & 5 \\
0,43 & 0,76 & 6 \\
0,34 & 0.78 & 7 \\
0,36 & 0,85 & 8 \\
0,36 & 0,85 & 9 \\
0,50 & 0.56 & 10 \\
0,40 & 0.81 & 11 \\
0,37 & 0,84 & 12 \\
0,42 & 0,78 & 13 \\
0,44 & 0,75 & 14 \\
0,37 & 0,84 & 15 \\
0,44 & 0,74 & 16 \\
0,45 & 0,28 & 17 \\
0,48 & 0,65 & 18 \\
0,49 & 0,62 & 19 \\
0,48 & 0,65 & 20
\end{tabular}




\begin{tabular}{lll}
0,31 & 0,90 & 21 \\
0,31 & 0,90 & 22 \\
0,26 & 0,93 & 23 \\
0,44 & 0,75 & 24 \\
0,47 & 0,69 & 25 \\
0,21 & 0,96 & 26 \\
0,34 & 0,78 & 27 \\
0,17 & 0,97 & 28 \\
0,48 & 0,66 & 29 \\
0,49 & 0,40 & 30 \\
0,50 & 0,49 & 31 \\
0,32 & 0,88 & 32 \\
0,40 & 0,81 & 33 \\
0,37 & 0,84 & 34 \\
0,49 & 0,63 & 35 \\
0,48 & 0,66 & 36 \\
0,24 & 0,94 & 37 \\
0,41 & 0,79 & 38 \\
0,47 & 0,69 & 39 \\
0,31 & 0,90 & 40 \\
0,40 & 0,81 & 41 \\
0,47 & 0,69 & 42 \\
5,76 & 31,28 & Self-steam \\
\hline
\end{tabular}

Question 2: What is the level of academic achievement among female students of the class- teacher in the scientific concepts and methods of teaching course?

In order to answer this question, the academic achievement scores for the study sample were obtained in a course of scientific concepts and methods of teaching at the end of the first semester of the academic year 2016/2017. The averages and standard deviations for their collection were calculated and Table 3 shows that.

Table 3. Grade achievement of female students of the class teacher in the scientific concepts and methods of teaching course end of the first semester of the academic year 2016/2017 and the averages and standard deviations of their achievement

\begin{tabular}{llll}
\hline percentage $\%$ & number & symbol & Grade/4 \\
\hline 26,5 & 18 & $\mathrm{C}$ & 1 \\
10,3 & 7 & $\mathrm{C}+$ & 1,5 \\
13,2 & 9 & $\mathrm{D}+$ & 2,5 \\
19,1 & 13 & $\mathrm{~B}$ & 3 \\
23,5 & 16 & $\mathrm{~B}+$ & 3,5 \\
7,4 & 5 & $\mathrm{~A}$ & 4 \\
100,0 & 68 & Total & \\
2,44 & & average & \\
8,19 & & standard deviations \\
\hline
\end{tabular}

The average score for the grades of the male students of the class teacher in the course of scientific concepts and methods of teaching $(2,44)$ which is a satisfactory average, as the percentage showed that $50 \%$ of the students of scientific concepts were grades (B) and above.

Question 3: Is there a relationship between the level of self-esteem and academic achievement among the female students of the class- teacher in the scientific concepts and methods of teaching course?

To answer this question Pearson correlation coefficient was extracted between female students' achievement in a course of scientific concepts and their self-esteem scores, Table 4 shows this. 
Table 4. The correlation between self - esteem and academic achievement among the students of the classteacher in the scientific concepts and methods of teaching material

\begin{tabular}{ll}
\hline Scientific Concepts & \\
\hline 0,29 & Coefficient of correlation \\
0,018 & Level of significance \\
68 & Number of individuals \\
\hline
\end{tabular}

The correlation between the students' academic achievement and their self-esteem was statistically significant. The coefficient of correlation among the female students in the scientific concepts course was 0.29 , which is statistically significant at a level below 0.05 , meaning that there is a positive relationship between the level of self-esteem and the degree of academic achievement.

\section{Discussion of the Results}

The results of the study were to reveal the level of self-esteem of the female students of the class teacher and their relation to the academic achievement. The results showed that $50 \%$ of the female students had high academic achievement and that $79.4 \%$ of the students received a high score. Such results were consistent with the results of (Aryana, 2010; Ashtiani, 2007 \& Naderi, 2009), the study also found that the relationship between the level of self-steam and academic achievement was positive and accelerated. The researcher attributed these results to the fact that most of the female students had high secondary school achievement, which was a driving force for female students to maintain their academic level. This result can also be attributed to their feeling that they have become at an important stage in their lives as well as the nature of the scientific material contained in the course which was interesting and interesting.

The reason for the high self-esteem of the teacher's female students can be attributed to the academic success of their undergraduate studies. Self-esteem works as a driving force for achieving greater success in line with positive individual self-evaluations while high academic achievement contributes to self-image enhancement In the individual and his assessments. Those who received an average grade of $20.6 \%$ had a lower secondary education than those who received high grades. They were less interested in studying or because they were forced to do so, thus showing a lack of interest in achievement. This was reflected in their academic achievement.

\section{Recommendations}

The results of this study are specific in their procedures and the nature of their sample. Therefore, the researcher recommends conducting further studies in this field and dealing with the relation of self-steam with other variables such as the degree of understanding of science processes and the degree of understanding of the nature of science.

\section{References}

Abu, J., \& Fawaz, R. (2003). The concern of the students of the State College of Education in Gaza and its relation to self-esteem and some other variables, unpublished master thesis, Al-Quds Open University, Gaza.

Abu, Z., \& Ibrahim, A. (1987). Psychology of Self and Consensus, Alexandria: Dar Al Maarefah.

Arabiyat, A., \& Zoghul, E. (2008). Differences in Self Esteem Level among Mo'tah University Students by Sex, Specialization and Educational Level. Journal of Educational and Psychological Sciences, 9(1), 39-53. College of Education, University of Bahrain.

Arvaneh, D., Mojgan, Amirian, Z., \& Bahador, C. (2017). Study the Relationship between Self-Esteem and Academic Achievement among High School Students in Lamerd City. International Journal of Scientific Study, 3(5), 221-226.

Aryana, M. (2010). Relationship Btween Self-Steam and Academic Achievement Amongest Pre-University Students. Journal of Applied Sciences, 10(20), 2474-2477.

Ashtiani, A., Ejei, J., Khodapanahi, M., \& Tarkhorani, H. (2007). Relationship Between self-concept, self-concept, Anxiety, Depression and Academic Achievement in Adolescents. Journal of Applied Sciences, 7(7), 995-1000.

Bankston, C. L., \& Zhou, M. (2002). Being well vs. doing well: Self-esteem and school performance among immigrant and non-immigrant racial and ethnic groups. International Migration Review, 36, 389-415. 
Fahmi, M. (1979). Mental Health - A Study in the Psychology of Adaptation, Cairo: Modern Arabic Press.

Ghanaim, A. (2010). Self-Esteem and its Relation to Achievement and Social and Economic Level among High School Students in the Acre Region, Unpublished Master Thesis, Amman Arab University for Graduate Studies, Amman, Jordan.

Gilani, G. (2016). Educational Achievement, I2, Dar Al-Masirah Publishing and Printing, Jordan.

Habibollah, N., Rohani, A., Tengku, H., Jamaluddin, S., \& Kumar, V. (2009). Self Esteem, Gender and Academic Achievement of Undergraduate Students. American Journal of Scientific Research, (3), 26-37.

Katrin, A., Seeshing, A., Nagengast, B., \& Hasselhorn, M. (2013). Relationship between self-esteem and academic self-concept for German elementary and secondary school students. International Journal of Experimental, Educational Psychology, 33(4), 443-464.

Margaret, Z., \& Jean, M. (2011). Self-esteem and academic achievement: a comparative study of adolescent students in England and the United States. Journal of Comparative and International Education, 41(5), 629-648.

Marjorie, S., Philip, P., Herbert, W., Rhonda, G., \& Alexander, S. Y. (2014). The reciprocal relations between self-concept, motivation and achievement: juxtaposing academic self-concept and achievement goal orientations for mathematics success. International Journal of Experimental Educational Psychology, 34(1), 49-72.

Marsh, H. W. (1990). Causal ordering of academic self-concept and academic achievement: A multi waive, longitudinal panel analysis. Journal of Educational Psychology, 82, 646-656.

Martins, M., Peixoto, F., Pereira, M., Amaral, V., \& Pedro, I. (2010). Self-esteem and Academic Achievement Among Adolescents. International Journal of Experimental Educational Psychology, 22(1), 51-62.

McDanel, L. (1973). Inferred self-concept: scale and manual. W.P.S. losangles. USA.

Rahmani, P. (2011). The relationship between self-esteem, achievement goals and academic achievement among the primary school students. Procedia - Social and Behavioral Sciences, (29), 803-808.

Return, A., \& Mkawi, F. (1992). Fundamentals of Scientific Research in Education and Human Sciences, Kanani Library, Irbid, Jordan.

Rosenberg, M. (1963). Society and tAdolescent, 2Edn., London: Penguin Books.

Saleh, A. (1995). Self-Esteem Scale for University Students. Journal of Psychological and Educational Evaluation, 3(6).

Shaqfa, A. (2008). Self-Esteem and Its Relation to Political Participation in the Open Jerusalem Students in Gaza, Unpublished Master Thesis, Gaza, Palestine.

van Laar, C. (2000). The Paradox of Low Academic Achievement but High Self-Esteem in African American Students: An Attributional Account. Educational Psychology Review, 5(1), 33-61.

Vialle, W. J., Heaven, P. C. L., \& Ciarrochi, J. V. (2005). The relationship between self-esteem and academic achievement in high ability students: Evidence from the Wollongong Youth Study. Australasian Journal of Gifted Education, 14(2), 39-45.

Vishalakshi, K., \& Yeshodhara, K. (2012). Relationship Between Self Esteem and Academic Achievement of Secondary School Students. Indian Journal of Applied Research, 1(12).

Wiggins, J., \& Schatz, E. L. (1994). The relationship of self-esteem to grades, achievement scores and other factors critical to school success. School Counselor, 41, 239-244.

Worrell, C. (2007). Ethnic identity, academic achievement, and global selfconcept in four groups of academically talented adolescents. Gifted Child Quarterly, 51(1), 23-38.

\section{Copyrights}

Copyright for this article is retained by the author(s), with first publication rights granted to the journal.

This is an open-access article distributed under the terms and conditions of the Creative Commons Attribution license (http://creativecommons.org/licenses/by/4.0/). 